\title{
Soundscape of the West Lake Scenic Area with profound cultural background-a case study of Evening Bell Ringing in Jingci Temple, China”
}

\author{
Jian $\mathrm{GE}^{\dagger 1,2}$, Min GUO ${ }^{1,2}$, Miao YUE ${ }^{1,3}$ \\ ( ${ }^{1}$ Deptartment of Architecture, Zhejiang University, Hangzhou 310058, China) \\ ( ${ }^{2}$ State Key Lab of Subtropical Building Science, South China University of Technology, Guangzhou 510640, China) \\ $\left({ }^{3}\right.$ Deptartment of Architecture and Art, Zhejiang College of Construction, Hangzhou 311231, China) \\ †E-mail: gejian1@zju.edu.cn \\ Received June 25, 2012; Revision accepted Sept. 27, 2012; Crosschecked Feb. 22, 2013
}

\begin{abstract}
From the case study of Evening Bell Ringing at Nanping Hill, one of the West Lake Cultural Landscapes in Hangzhou, China, we investigated the soundscape of a scenic area with a profound cultural background. First, we conducted the soundscape physical index of the area in both winter and spring seasons to analyze its objective graphical expression. Second, we focused on people's reactions to the soundscape in order to obtain a subjective evaluation of each component in the soundscape and integrated environment. Then, the relationship between the objective data and the subjective evaluation was analyzed. Finally, the impacts of the natural environment, history, and cultural factors on the evaluation of the Jingci Temple soundscape were studied. It was found that natural sounds, cultural sounds, and historic sounds were widely acclaimed in people's subjective feelings, which indicated the close relationships among historical and cultural background, soundscape, and natural environment. Thus, the conclusion was made that soundscape should be consistent with the local natural environment and the historical and cultural background.
\end{abstract}

Key words: Soundscape, Culture, Evaluation, West Lake, Evening Bell Ringing at Nanping Hill doi: $10.1631 /$ jzus.A1200159

Document code: A

CLC number: TU986

\section{Background}

\subsection{Concept of soundscape}

Different from the long-term focusing on visual elements in traditional landscape design, the concept of soundscape suggests "sound" as an important landscape component, and comprehensive soundscape design can improve the compatibility of an acoustic environment in a landscape.

Soundscape research mainly focuses on evaluation and application. However, the relationship be-

\footnotetext{
* Project supported by the National Natural Science Foundation of China (No. 51078325), and the State Key Lab of Subtropical Building Science, South China University of Technology, China

(C) Zhejiang University and Springer-Verlag Berlin Heidelberg 2013
}

tween culture and soundscape is rarely mentioned. This is particularly significant in Chinese sites of profound cultural background.

\subsection{Soundscape evaluation research}

\subsubsection{Objective evaluation of soundscape}

The objective evaluation of sounds capes cannot be simply supported by physical parameters of auditory sense (Genuit, 1999; Raimbault et al., 2003). Based on background and transport noise, soundscapes can be classified into the following five classes: very quiet area, quiet area, elevated loudness in the area, loud area, and very loud area (Lebiedowska, 2005). For quantitative description of soundscape, Botteldooren et al. (2006) researched the descriptors for the temporal structure of urban soundscape and 
especially focused on traffic noise. Rychtáriková and Vermeir (2013) proposed a soundscape assessment method based on multi-parameter analysis of 13 acoustic parameters which directly related to human perception of sound. The temporal element is composed of stabilization time, short-term temporal variability, and sound pressure level (SPL) impulsiveness. Torija et al. (2011) studied the effect of temporal composition on urban soundscape description and perception.

\subsubsection{Subjective evaluation of soundscape}

The subjective evaluation of soundscape is also an important aspect. Yang and Kang (2005) indicated two important indexes in subjective soundscape evaluation in urban open public space. One was sound level, and the other was the sound source types. It was found that a pleasant sound can be felt more acoustically comfortable even it is of a high sound level. According to the research of semantic differential analysis of soundscape, the major factors of description and evaluation can be identified as relaxation, communication, spatiality, and dynamics. Compared to the general public, designers have more diverse evaluation criteria and stronger preferences to green spaces and natural sounds (Kang and Zhang, 2010). By the multiple surveys done in Europe and China, it is indicated that social, demographical, physical, behavioral, and psychological factors should be the ones that influence sound preference in urban open space (Yu and Kang, 2010). Brown et al. (2011) considered that soundscape study involved diverse laws, approaches and fields of practice. The fields overlapped not only in environmental noise management, human acoustic comfort in buildings and sound quality, but also in landscape planning and management, urban and building design and wilderness and recreation management. Hall et al. (2013) used statistical methods to examine a range of psychoacoustic, perceptual and acoustic properties. The perceived soundscape quality as an individual subjective experience was influenced by personal preference, social, cultural and historical factors.

\subsubsection{Visual environment and soundscape evaluation}

Viollon et al. (2002) found negative sound ratings for a natural sound environment within an urban visual setting. Meanwhile, if the sound included human sounds, the evaluation depended on the per- ceiver's implication of the sound environment, and the degree to which visual and sound information coincided. Due to the increased prevalence of sensory overloading in modern society, people need sufficient sensory stimulation to keep engaged, but also need opportunities for the reflection and relaxation. Pheasant et al. (2010) researched audio-visual interaction of the tranquility perception, and then identified acoustic information as an integral part in perception.

\subsection{Soundscape application}

\subsubsection{Noise control}

Previous studies on urban noise have been criticized for a number of inherent weaknesses. These surveys were categorized into four types. Some suggestions were given to make the noise surveys more efficient, such as disaggregation of noise by source type (Brown and Lam, 1987). The road traffic noise condition in Curitiba was investigated by the improved German Standard RLS-90 noise statistical modeling (Calixto et al., 2003). Soundscape studies can theoretically and technically benefit noise control. Noise level reduction alone will not necessarily lead to improved quality of life and economy efficiency. Soundscape approach pays attention to the relationship between human beings, ear, sound environments, and society (Kang, 2011). Zhou and Gai (2005) provided a new paradigm of noise control combining creativity, relationship, and sociability.

\subsubsection{Design application}

Raimbault and Dubois (2005) assessed the sound phenomena in daily life and discussed the concept of soundscape as structuring the sound space category. Yamada (2006) proposed a new method based on a soundscape approach to improve walking routes layout in forests.

\subsubsection{Relative works}

Ge and Hokao (2004) conducted several surveys on the Saga Forest Park soundscape. The surveys purposed to identify the structures of the soundscapes of urban parks as well as preference and congruence of each component in a soundscape. They also analyzed the soundscape spatial formation and the relative importance of each component. The presence of ground traffic, air traffic, and human voices 
negatively impacted environmental assessments, and increased ratings of hostility, especially in scenic beauty (Benfield et al., 2010). Szeremeta and Zannin (2009) investigated the sound environment using a soundscape study model, and concluded that park sound environments were determined by those factors jointly interfering in their perception and in the soundscape. The factors included the urban surroundings environment, the space of parks and the sounds originating inside the parks.

\subsection{Humanism of soundscape and environment}

\subsubsection{Humanism of soundscape worldwide}

In the management of the soundscape of US National Parks, the conflict between the natural sound experience and traditional sound-making human activities was investigated (Miller, 2008). On June 25, 2002, the European Parliament and Council adopted Directive 2002/49/EC, relating to the assessment and management of environmental noise. EU Noise Directive gives attention to the subjective evaluation of the public, and has a goal of "informing and consulting the public". When addressing local noise issues, the directive gives enough respect to the local competent authorities (European Commission, 2002). In 1996, the Ministry of Environment of Japan openly recruited people throughout the country concerned with the importance of local characteristics to compile a list of soundscapes deserving preservation. One hundred significant soundscapes with particularly cultural meanings were identified from those suggested by the public (Wikipedia, 1996).

\subsubsection{Soundscape in Chinese culture}

There are numerous ties between traditional Chinese culture and many varied soundscapes across China. The well-known saying "Cicada sounds silence the woods; bird chirps sequester the mountains", is one example. There are some famous verses containing references to soundscape culture. "Guanguan goes the ospreys, on the islet in the river" (Song, 1988), where guan-guan refers to the sound of bird chirping. "No need for stringed or woodwind instruments, the landscape can play" (Zhang, 2007) implies a pleasant description of people's feelings towards the sounds of nature. Well "Outside of Gusu City, an ancient temple sits still and lonely as the midnight clock chimed at my ship" reflects that people are also affected by artificial sound.

Musical and poetic expressions of landscape appreciation have been present as emotional expressions before the concept of soundscape was put forward. "Two yellow orioles in the tender green willow, a line of herons crosses the blue sky" (Sun, 1994), and "the stream embraces pebbles and makes ring-bell sounds; beautiful birds sing to each in chirpy melody" (Qian, 1988) both vividly express the blending of sound and scene. There are also some deliberately described sounds, e.g., "one does not live in vain to have heard the sound of chess in daytime, the sound of flute in moonlight, the sound of winds whistling through the pines in the mountains, and the sound of rowing oars from the opposite bank" (Zhang, 2001).

Certain sceneries are famous for certain sounds, such as Spring-rain Lofty and the Place for Listening to the Pine Wind in the Humble Administrator's Garden, Suzhou, Music Mountain Stream in Jichang Garden, Wuxi, Surging Waves Pavilion, Suzhou, "bamboo soughing sounds as flute playing; stream flowing rings like zither performing". Moreover, Predecessor LI Dao-yuan (AD 472-527, Northern Wei Dynasty), in his prose works of geography Shuijing Zhu asserted, “...the mountain is above an unfathomable pool, in which breeze raises waves; water and rocks collided each other, producing sound of bell. Therefore, it was named Bell Rock" (Li, 1966).

The West Lake Scenic Area with its long history and rich cultural deposits spurs poets and wordsmiths to compose splendid words and phrases, not lacking in the depiction of sounds. "The water is calm as mirror, boats slide on the surface, and the 'Ai Nai' sound of the dip of the oars picks up the peaceful and secluded lake" (Zong, 1981). One of the Ten Scenic Spots within the area, "Evening Bell Ringing at Nanping Hill" is regarded as a tourist attraction where visitors can appreciate the sounds of scriptures being recited or bells ringing. People experience these artistically inspiring events through their auditory senses. On June 24, 2011, the West Lake Cultural Landscape of Hangzhou was named to UNESCO's World Heritage List. Representing Chinese aesthetics and philosophy, the surroundings of West Lake were recognized as an extraordinary cultural landscape.

Evening Bell Ringing at Nanping Hill, with the word "Bell", intending to create a place for people to 
hear and understand the temple and bell in nature, is a model of sound-in-landscape in history. "The distant temple bell is resonant in the twilight, and the trees in the distance are deep and serene. The returning monks cross the river and birds and beasts go back to forest, when cold smoke is flowing out of the autumn hill" (Shi, 2006b). "The bell ringing was delivered across the lake, from the heavens" (Zhang, 1995). "The bluish green screen (Nanping Hill) turned into thousand-layer white jades; the bell tower is close, while the ringing of modulation in tone spreading widely makes me so confused; after the 108 peals, the antique lamp of the Leifeng Pagoda was lit up..." (Shi, 2006) vividly depicts the subtle relationship between landscape and soundscape, and the individuals experiencing them. "The clouds wafting in the air encircled the Leifeng Pagoda, and wind carried the bell ringing to the windows of quiet dwellings. The crowd evaporated in the misty willows in concert with the sight that a monk struck the bell in the moonlight" (Fu, 1878). "The shade of the bell tower shelters the monks in peace; the ringing pierces the sky of sunset" convey the quiet and fine artistic conception of natural sounds. "On the Nanping hill, there centered a Buddhist temple. A new bell mould shaking the universe. Sound spreads, like God appears for Salvation" (Shi, 2006). "This place is such a paradise with beautiful sceneries. You may invite recluses with no fixed abode or occupation to listen to Huiri bell of 108 peals". "The will of God stays onhills; the mind of Buddha baptizes (creatures) by rings". The charm and beauty of Buddha in this place deepen its cultural deposits.

\subsection{Focus of this study}

From the temple park case study of Evening Bell Ringing at Nanping Hill, the West Lake Cultural Landscape, Hangzhou, this research was conducted with the following objectives:

1. The soundscape physical index of the area in winter and spring, and its objective graphical expression;

2. People's receptions to the soundscape and subjective evaluation of each component in soundscape and the integrated environment;

3. The relationship between objective data and subjective evaluation;

4. The impacts of the natural environment and history and culture factors on the soundscape.

\section{Methodology}

\subsection{Study areas}

The West Lake Scenic Area, located in the historic center of Hangzhou, Zhejiang province of eastern China, is the national key scenic area. Not only a picturesque landscape, the West Lake Scenic Area is also famous for its influence upon Chinese culture and is associated with many scholars, national heroes, and revolutionary martyrs. The West-Lake-centered scenic area covers an area of $60 \mathrm{~km}^{2}$ with the lake surface itself occupying $5.68 \mathrm{~km}^{2}$. "Evening Bell Ringing at Nanping Hill" is one of the ten scenic spots at the West Lake since the Southern Song Dynasty (AD 1127-1279).

The Nanping Evening Bell is situated at the famous Jingci Temple, behind the Leifeng Pagoda. The temple leans against Nanping Hill, facing to the West Lake in the north, surrounded by hills and the lake (Fig. 1). The sceneries such as the hills, the lake, and the plants, with the bell ringing of the Jingci Temple, achieve a perfect combination of the visual landscape and soundscape. "Evening Bell Ringing at Nanping Hill" actually refers to the bell ringing from the Jingci Temple. The enduring ringing sounds distant and gently flowing with a range of pitch that is sometimes low and sometimes high. The bells can be heard across the entirety of the lake's surface. The shape of Nanping Hill is similar to that of a painted screen. Therefore, when the bell is rung in the evening, its sonorous sound echoes through the caves and cavities and is enhanced by resonance effect. The ringing transmits on the lake surface and reaches as far as Precious Stone Hill on the other shore of West Lake. The effusive rock formation of Precious Stone Hill returns the bell sounds over the lake in echoes which cross and form strong reverberations.

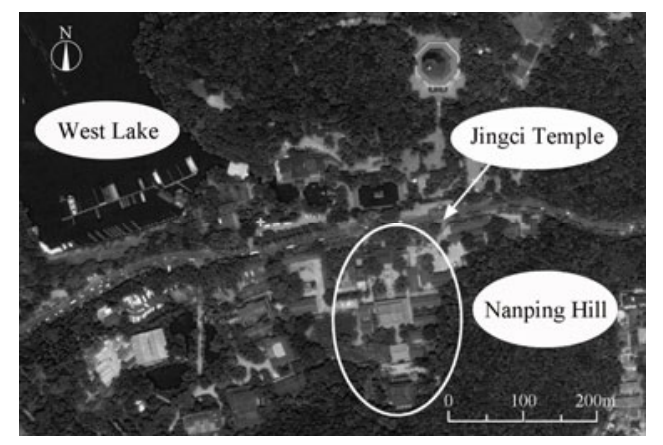

Fig. 1 Location and environment of Jingci Temple 
The bell is routinely struck twice a day, during the morning recitation and the evening recitation. Additionally, during the daily opening hours, tourists may donate money and strike the bell praying for good luck. Every Chinese New Year's Eve, 108 peals of the bell welcome the New Year. The bell ringing symbolizes the sweeping away of the old and starting afresh, incorporating themes of peace, happiness, stability and unity.

\subsection{On-site investigations}

On-site investigations were conducted twice on Dec. 28, 2009 and May 21, 2011 to inquiry the general conditions of the park, especially the components and structure of its soundscape. Studies were carried out from 10:00 to 15:00 in winter (low-season for tourism) and spring (high-season for tourism); the test objective was the acoustic environment inside Jingci Temple. The meshing of the plan was $10 \mathrm{~m} \times 10 \mathrm{~m}$ each grid and totally divided into 90 points, and measured by AWA6270+ABC sound-level meter at the centre of each one for $1 \mathrm{~min}$, A-weighted equivalent SPL (Leq), instantaneous SPL (Lp), and the sound sources were recorded. Two surveyors each holding an adjusted sound-level meter began to measure simultaneously in different grids, which could help to catch the main sound components and their structure, and also serve as a base for the following questionnaire surveys.

\subsection{Interview}

Questionnaire surveys to visitors were conducted on May 21, 2011. The target audience of the interview was tourists and temple staff. Three specialized investigators simultaneously started a random survey, handing out 60 copies of valid questionnaires, with a retrieval ratio of $100 \%$. All copies of the survey were distributed to visitors. After the approval of the workers in the Jingci Temple, three investigators randomly looked for visitors inside the temple and handed out questionnaires. Although the Nanping Evening Bell is famous, the Jingci Temple itself is not a hot spot, and the visitors need to buy tickets to enter. Thus, the visitors in this temple are all particular audiences of its soundscape. While the visitors filled out the questionnaires, our staff gave individual attention to the respondents in order to answer questions, and to ensure the authenticity of the questionnaires.
The questionnaire investigated the following: (1) Personal properties of visitors; (2) Evaluation of the sound they heard in the park with sequence in terms of "loudness", "impression", "preference", and "congruence"; and, (3) Semantic differential profiles of the park sound environment with 12 pairs of adjectives with a seven-point-scale.

\section{Results}

\subsection{Components of soundscape}

From the on-site investigations, the main components and structure of the soundscape are identified (Table 1). They are divided into three types according to sound source: natural sound, artificial sound and social sound.

Table 1 Main components of the soundscape in the Jingci Temple

\begin{tabular}{lll}
\hline Natural sound & Social sound & Artificial sound \\
\hline Wind blowing, & Sound of chil- & Traffic sound \\
tree rustling, bird & dren, talking & from outside, \\
and insect twit- & voice, Buddhist & bell ringing, \\
tering, water & chanting, foot- & broadcast \\
flowing & steps, singing & sound, music \\
\hline
\end{tabular}

\subsection{Sound pressure level}

Colored by painting software Photoshop, sound pressure level grid measure diagrams and SPL values are displayed in Fig. 2 and Fig. 3, describing the SPL distribution status. The figures show that the SPL level in peak-season of spring is generally $5 \mathrm{~dB}$ higher than that in the winter tourism off-season.

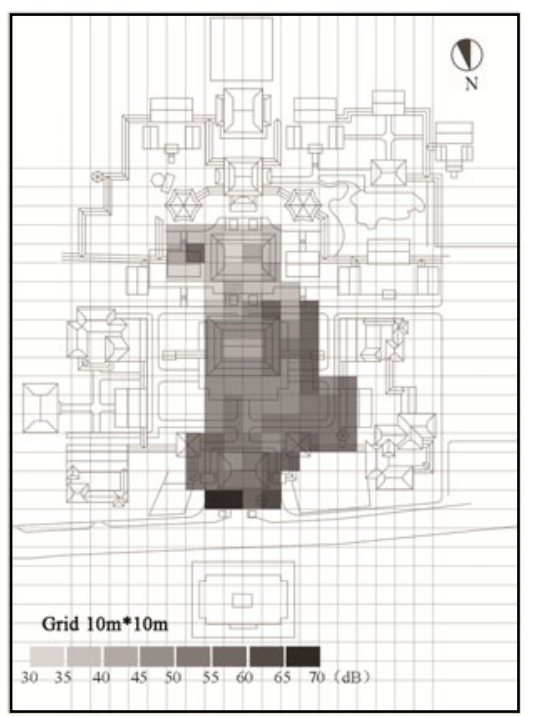

Fig. 2 SPL values plan schematic diagram (winter) 


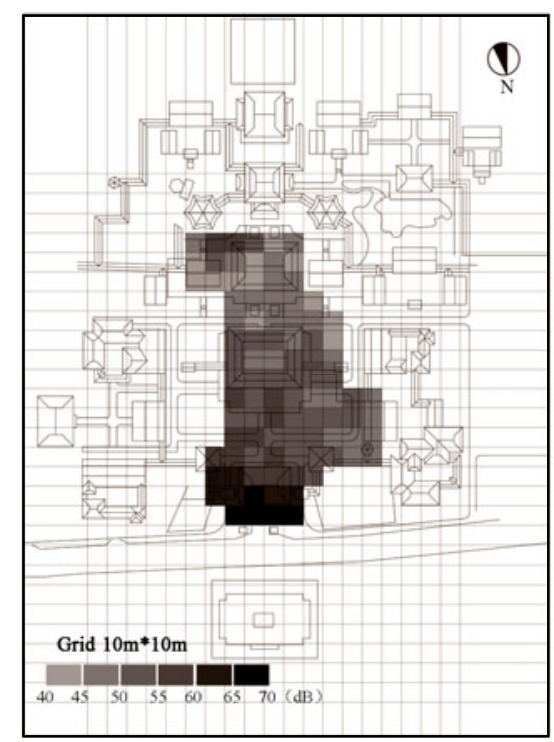

Fig. 3 SPL values plan schematic diagram (spring)

According to the enclosed arrangement of the buildings and landscape characteristics, the open spaces in the Jingci Temple can be divided into five types: busy entrance, lively hall front-square, bell tower, quiet woods, and hall back-square. The busy entrance is a place for people to walk through and it is near the trafficked road outside. The lively hall front-square is the largest square in the temple. It is in the center of the temple, surrounded by the main buildings, where most tourists concentrate their visit. The bell tower, which houses the famous bell, is covert and at one side of the temple with fewer visitors. The quiet woods are deep in the temple, and with trees but few tourists. The hall back-square is at the back of the temple, also surrounded by some main buildings. Since these buildings are under renovation, there are few people in this square. These five zones are marked out (Fig. 4).

According to the sound pressure level grid measure diagram and SPL values, the general SPL of the five types of zone decrease successively about $5 \mathrm{~dB}$ in spring, i.e., SPL of the busy entrance $>$ SPL of the lively hall front-square $>$ SPL of the bell tower $>$ SPL of the hall back-square $>$ SPL of the quiet woods. But in winter the decrease becomes steeper as $10 \mathrm{~dB}$, and the order of the SPL of the lively hall front-square and the bell tower reverses.

There is a larger gap in the SPL of the bell tower when the bell is ringing or not: in winter was $L p$ $58.4 \mathrm{~dB}(\mathrm{~A})$ when bell was ringing and Leq
$49.8 \mathrm{~dB}(\mathrm{~A})$ when not ringing, while in spring the number was Lp $62.3 \mathrm{~dB}(\mathrm{~A})$ and Leq $53 \mathrm{~dB}(\mathrm{~A})$.

Fig. 5 shows the SPL variation diagram of depth, and three features can be detected. First, the SPL of each measurement point is generally higher in spring than that in winter. Second, the SPL variation is regular in both spring and winter, and the change rate of values is basically due to the distance from the spot to the street. From the street to the internal areas of the temple, the SPL changes according to "highesthigh-lowest-low", which is in accordance with the SPL variation that "SPL of the busy entrance $>$ SPL of the lively hall front-square $>$ SPL of the hall backsquare $>$ SPL of the quiet woods". Finally, the SPL variation curve is flatter in spring than in winter. In winter, the SPL curve can be clearly divided into four ladders, i.e., $67.9 \mathrm{~dB}, 52.9-55.9 \mathrm{~dB}, 47.5-49.1 \mathrm{~dB}$, and $34.0-38.5 \mathrm{~dB}$. However, in spring, the SPL curve is more like a continuous diagonal.

\subsection{Interview data of subjective evaluation}

The subjective evaluation component of this study consisted of three parts. First, the personal properties of visitors, including gender, age, educational background and frequency of coming to the West Lake, were studied. In this interview, male subjects constituted the main part, with the percentage of $58 \%$. The ages of the subjects ranged from 20 to $64.75 \%$ or 45 subjects have obtained associate college degree or above, and $67 \%$ or 40 come to the West Lake once or more per month.

The second part made inquiries about the sounds that can be heard in the park and an evaluation of the sound components in the park with sequence in terms of "impression", "loudness", "preference", and "congruence". The responders were asked to pick out seven sound components according to our question "which sound can be heard" and sequencing these sound components according to the four terms mentioned above.

Fig. 6 shows the total frequency of sound mentioned by people according to our question "which sound can be heard" in survey, which including wind blowing, tree rustling, bird chirping, insect twittering, talking voice, Buddhist chanting, footsteps, bell ringing, and traffic sounds.

To analyze the important indices of evaluation "preference" and "congruence" with scoring from 1 


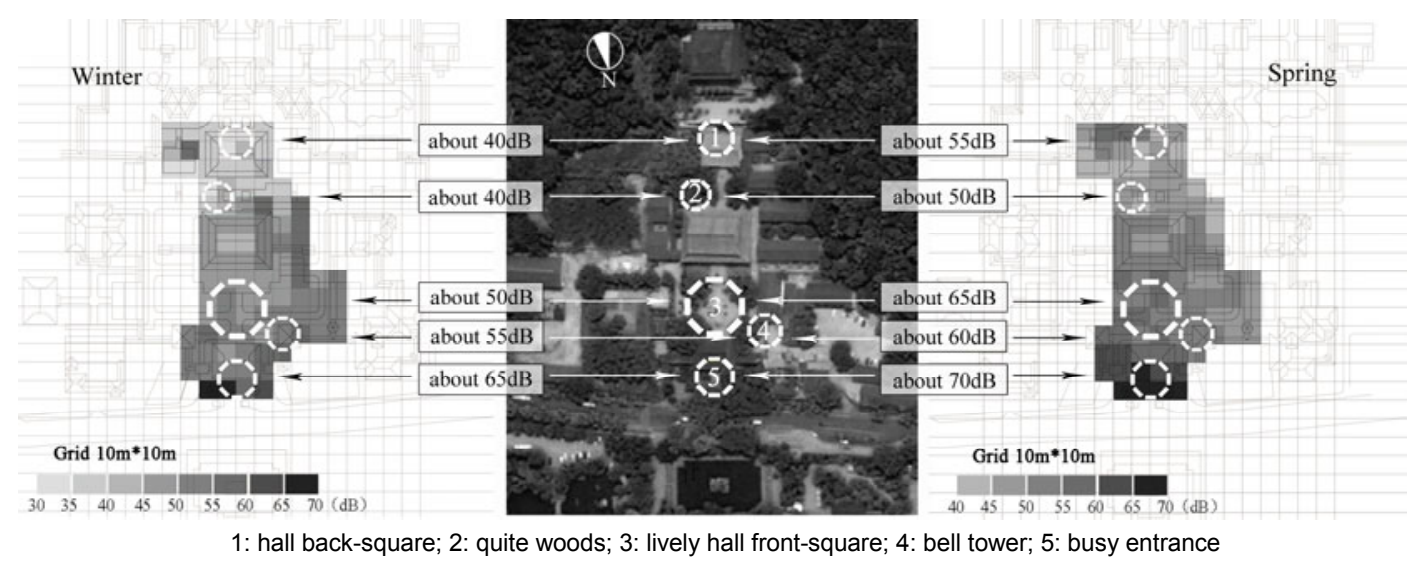

Fig. 4 Measuring plan and aerial map of divided types of zone in winter and spring
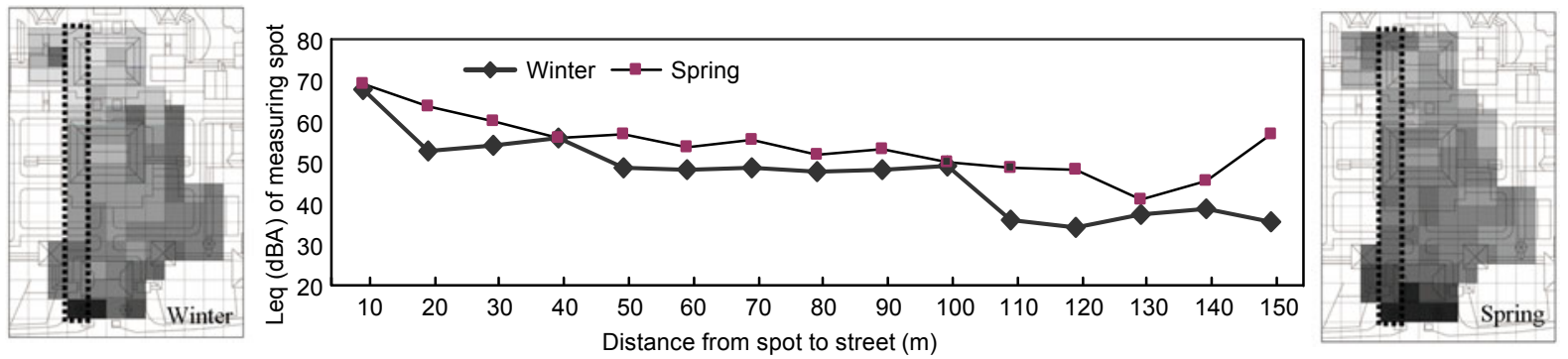

Fig. 5 SPL values variation diagram of depth in plan (winter and spring)

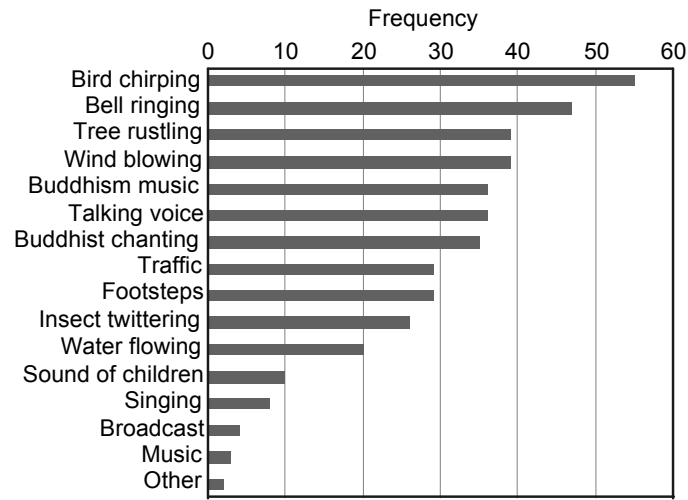

Fig. 6 Frequency of sound mentioned by interviewees

to 7, the level increases with the value increasing ("7" being most preference and congruence, and 1 being least preference and congruence), we obtained average scores as shown in Fig. 7. It is worth noting that "preference" and "congruence" scores were very similar for all sounds.

Tree rustling, bird chirping, wind blowing, Buddhist chanting, Buddhism music, and bell ringing are listed as positive-evaluated objects; on the contrary, children's voice, chatting, footsteps, singing, and traffic sound are negative-evaluated objects.

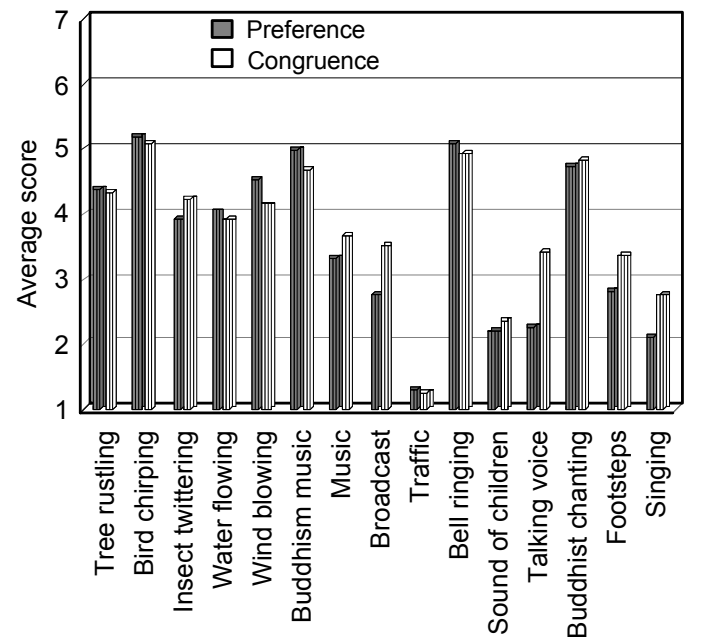

Fig. 7 Preference and congruence evaluation of sound components

The third is semantic differential profile of the sound environment of the park involved an evaluation with 12 pairs of adjectives with a seven-point-scale. By selecting adjectives consistent with the level felt, the respondents evaluate the acoustic environment subjectively. Fig. 8 shows that the Jingci Temple is likely to be described as "quiet", "natural", 
"information contained", "tranquil", "pure", "distant", "tardy", and "soft" in the semantic segmentation evaluation, and is generally inclined to be "congruent", "favorite", "satisfying", and "related to visual environment".

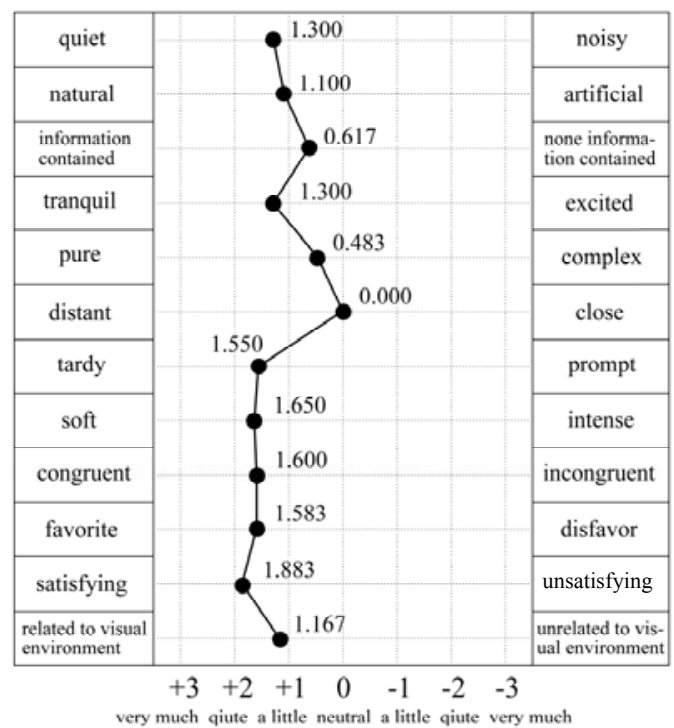

Fig. 8 Semantic differential profiles of soundscape

\section{Discussion}

\subsection{Objective results}

Three main findings can be obtained from the objective SPL research. The first finding is that the SPL of each measurement point is generally higher in spring than that in winter. This is because spring is the peak tourist season. Compared to the winter offseason, more tourists visit in spring and create more social sounds. For natural sounds, spring is a season of great growth and reproduction for both plants and animals. Thus, as compared to winter, there are more natural sounds in spring. Surprisingly, traffic noises from street are roughly equivalent in both seasons resulting in similar SPL values in spring and winter.

The second point is that the SPL variation is regular in both spring and winter, as "SPL of the busy entrance $>$ SPL of the lively hall front-square $>$ SPL of the hall back-square $>$ SPL of the quiet woods". The sound environment inside the temple was mainly influenced by traffic from the northern street. The front-square and back-square of the hall are bustling with activities and people, resulting in talking and footsteps noises. The quiet woods are secluded, with few people and full of natural sounds. The loudness of the three types of sound source is shown as follows: artificial sound $>$ social sound $>$ natural sound. It proved that the SPL trend connects with the overall arrangement of the location.

The third point is that the SPL variation curve is flatter in spring than in winter. The traffic sound is the same in the two seasons. The social sound is slightly lower in winter than in spring because of the tourist reduction in winter. The natural sound is deeply influenced by seasons and is dramatically reduced in winter. As a result, in winter, the SPL gap between the natural sound, social sound, and artificial sound is wider, forming steps in the SPL values line. While in spring the gap is narrower and the variation tendency is gentle.

\subsection{Subjective results}

In the subjective research, the major components of the Jingci Temple soundscape indicated by the subjects interviewed are: the natural sounds of tree rustling, bird twittering, and wind blowing; the social sounds of talking voices, footsteps, and Buddhist chanting; and the artificial sounds of bell ringing and transportation.

Compared to the previous studies (Benfield et al., 2010; Kang and Zhang, 2010), the subjective result of different kinds of sound is coincident, i.e., the natural sounds are widely praised. Social sounds such as chatting and footsteps are negatively evaluated. Traffic sound is regarded as the most rejected sound. However, bell ringing, Buddhist chanting, and Buddhism music as special social and artificial sounds, which are widely praised by people, are the second, third, and fourth most favorably identified sounds. These are indications of the uniqueness of the Jingci Temple soundscape.

People's overall assessment of acoustic environment around Jingci Temple is "favorite", "satisfying", and "congruent". In semantic segmentation evaluation of the whole acoustic environment, the adjectives are "quiet", "natural", "tranquil", "pure", "distant", "tardy", and "soft".

\subsection{Relationship between objective and subjective results}

Comparing the results of the objective and subjective research, we found that at the identical spot, 
the SPL changes with seasons, and varies greatly when the bell is ringing or not: for instance, in winter when the bell is ringing the SPL is $\mathrm{Lp} 58.4 \mathrm{~dB}(\mathrm{~A})$, and Leq $49.8 \mathrm{~dB}(\mathrm{~A})$ when not; in spring, the values are $\mathrm{Lp}$ $62.3 \mathrm{~dB}(\mathrm{~A})$ and Leq $53 \mathrm{~dB}(\mathrm{~A})$. Although the bell ringing raises SPL by 8 to $10 \mathrm{~dB}$, it is still the second one among all the sound sources in the subjective evaluation ranking of "preference" and "congruence", next only to the birds chirping.

It seems that the social sound of Buddhist chanting in temple and the artificial bell ringing and Buddhism music are comparatively unique to the other common sounds in parks. There are two reasons for their high appreciation. On one hand, they are all distinguished from common sounds in daily life or irregular artificial sounds and they connote certain rules of rhyming and meaning. On the other hand, properties of the temple and the cultural content of the scenic spot create a profound artistic conception of harmony in nature.

\subsection{Impacts of environment, history, and culture on the soundscape}

The history and culture of the Jingci Temple, especially the Buddhism, play an important role in the subjective results. First, as evidenced by the survey results, the visitors of the temple are a unique subset of the general population. According to survey statistics, $67 \%$ of interviewees come to the Jingci Temple once or more every month. As compared to new visitors, these experienced visitors have an awareness of the Nanping Evening Bell and its history. They even expect a feeling of cleansing of the soul when the bell sounds. Second, the average acceptance of natural sound is up to $60 \%$, which indicates a preference for such sounds in this unique setting. In the fresh air and wonderful natural environment, people wish to sublimate their state of mind. They achieve this by appreciation of special cultural sounds, as the interview scores indicated greater than $67 \%$ preference for the bell peals, Buddhist chanting, and Buddhism music. The last point is that the education of $75 \%$ respondents is junior college or above. People nurtured by traditional Chinese culture, especially those who have experienced the artistic conception of poems and paintings, are more likely to perceive the elegance and pleasure of sounds in the scenery. Educational degree or acculturation of the respon- dents may play a role in positive evaluation of certain sounds, but further research is needed to confirm this assumption.

The regular SPL variation mainly shows the impacts of the environment on its soundscape. The affection for natural sound is also related to the geography and land features of the site. The Jingci Temple at "Evening Bell Ringing at Nanping Hill" of the West Lake Scenic spots is located on the south shore of the West Lake, back against Nanping Hill. Tourists are attracted by its ecological environment, and admire natural sounds that constitute a harmonious whole with the landscape.

According to the survey, people believe there is "congruence" between the soundscape and landscape. In further research, by operating a series of controllable factors in an experiment we will emphasize on the relationship between soundscape evaluation and visual environment to discuss the influence on soundscape evaluation by visual effect.

In conclusion, the acoustic environment that obtains recognition and favor usually contains cultural connotation which should be "congruent" to the visual environment.

\section{Conclusions}

The Jingci Temple is an urban scenic area with profound cultural background, and an urban treasure with salient local characteristics and deep cultural deposits. With respect to the temple's soundscape, the subject of study has social meanings with special acoustic elements, different from an ordinary open space or simple natural landscape.

From objective investigation, we found that the SPL distribution of the Jingci Temple changes regularly. This is mainly affected by the landscape distribution and the environmental changes caused over time on a seasonal basis. In the subjective evaluation, we established that natural sound is positively evaluated by temple visitors, while the evaluations of social sound and artificial sound are negative. This is also consistent with the natural landscape features in and surrounding the Jingci Temple.

The specific history and culture of Jingci Temple create some unique cultural sounds, such as bell ringing, Buddhist chanting, and Buddhism music. 
The SPL of these special sounds are generally high, especially for bell ringing. It raises 8 to $10 \mathrm{~dB}$ when the bell rings. However, the subjective evaluation of these special sounds is not influenced by the objective high SPL. This is caused by the impact of historical and cultural elements on the soundscape evaluation. Sounds in accordance with the historical and cultural connotation of the spot are more likely to get higher preference and congruence evaluation.

We conclude that the objective distribution and subjective evaluation of the soundscape are both influenced by the environmental landscape, and the historical and cultural connotation of the spot can also affect people's subjective evaluation of a soundscape.

In the future, it is important to coordinate a featured soundscape with the corresponding local culture, in order to understand people's feelings, and make the existing landscape design of the area perfect, hoping to exhibit a more fascinating West Lake Scenic Area to the world.

\section{References}

Benfield, J.A., Bell, P.A., Troup, L.J., Soderstrom, N.C., 2010. Aesthetic and affective effects of vocal and traffic noise on natural landscape assessment. Journal of Environmental Psychology, 30(1):103-111. [doi:10.1016/j.jenvp. 2009.10.002]

Botteldooren, D., De Coensel, B., De Muer, T., 2006. The temporal structure of urban soundscapes. Journal of Sound and Vibration, 292(1-2):105-123. [doi:10.1016/ j.jsv.2005.07.026]

Brown, A.L., Lam, K.C., 1987. Urban noise surveys. Applied Acoustics, 20(1):23-39. [doi:10.1016/0003-682X(87) 90081-8]

Brown, A.L., Kang, J., Gjestlandc, T., 2011. Towards standardization in soundscape preference assessment. Applied Acoustics, 72(6):387-392. [doi:10.1016/j.apacoust.2011. 01.001]

Calixto, A., Diniz, F.B., Zannin, P.H.T., 2003. The statistical modelling of road traffic noise in an urban setting. Cities, 20(1):23-29. [doi:10.1016/S0264-2751(02)00093-8]

European Commission, 2002. Noise: The Environmental Noise Directive. Environment. Available from http://ec. europa.eu/environment/noise/directive.htm [Accessed on June 4, 2012].

Fu, W.L., 1878. Record of the West Lake. Zhejiang Publishing House, Zhejiang, China, p.26-27 (in Chinese).

Ge, J., Hokao, K., 2004. Research on the sound environment of urban open space from the viewpoint of soundscape-A case study of Saga Forest Park, Japan. Acta Acustica United with Acustica, 90(3):555-563.

Genuit, K., 1999. The Use of Psychoacoustic Parameters Combined with A-Weighted SPL in Noise Description.
Internoise, Fort Lauderdale, Fl USA, p.1887-1892.

Hall, D.A., Irwin, A., Jones, M.E., Phillips, S., Poxon, J.E.W., 2013. An exploratory evaluation of perceptual, psychoacoustic and acoustical properties of urban soundscapes. Applied Acoustics, 74(2):248-254. [doi:10.1016/j. apacoust.2011.03.006]

Kang, J., 2011. Noise Management: Soundscape Approach. Encyclopedia of Environmental Health. In: Nriagu, O.J. (Ed.), Elsevier Science Ltd., Amsterdam, p.174-184.

Kang, J., Zhang, M., 2010. Semantic differential analysis of the soundscape in urban open public spaces. Building and Environment, 45(1):150-157. [doi:10.1016/j.buildenv. 2009.05.014]

Lebiedowska, B., 2005. Acoustic background and transport noise in urbanised areas: A note on the relative classification of the city soundscape. Transportation Research Part D: Transport and Environment, 10(4):341-345. [doi:10.1016/j.trd.2005.03.001]

Li, F., 1966. The Cream of Literary World. China Publishing House, Beijing, China, p.4394 (in Chinese).

Miller, N.P., 2008. US National Parks and management of park soundscapes: A review. Applied Acoustics, 69(2):77-92. [doi:10.1016/j.apacoust.2007.04.008]

Pheasant, R.J., Fisher, M.N., Watts, G.R., Whitaker, D.J., Horoshenkov, K.V., 2010. The importance of auditoryvisual interaction in the construction of 'tranquil space'. Journal of Environmental Psychology, 30(4):501-509. [doi:10.1016/j.jenvp.2010.03.006]

Qian, B.C., 1988. Gems from Chinese Culture. Shanghai Ancient Books Publishing House, Shanghai, China, p.494 (in Chinese).

Raimbault, M., Dubois, D., 2005. Urban soundscapes: Experiences and knowledge. Cities, 22(5):339-350. [doi:10. 1016/j.cities.2005.05.003]

Raimbault, M., Lavandier, C., Berengier, M., 2003. Ambient sound assessments of urban environments. Applied Acoustics, 64(12):1241-1256.

Rychtáriková, M., Vermeir, G., 2013. Soundscape categorization on the basis of objective acoustical parameters. Applied Acoustics, 74(2):240-247. [doi:10.1016/j.apacoust. 2011.01.004]

Shi, D.H., 2006a. Record of Nanping Jingci Temple. Hangzhou Publishing House, Hangzhou, China, p.57 (in Chinese).

Shi, J.X., 2006b. Record of Jingci Temple. Hangzhou Publishing House, Hangzhou, China, p.316 (in Chinese).

Song, Y.R., 1988. The Book of Songs. Tianjing Xinhua Bookstore Publishing House, Tianjin, China, p.1 (in Chinese).

Sun, Z., 1994. 300 Tang Poems Continuation. Zhejiang Ancient Books Publishing House, Hangzhou, China, p.186 (in Chinese).

Szeremeta, B., Zannin, P.H.T., 2009. Analysis and evaluation of soundscapes in public parks through interviews and measurement of noise. Science of The Total Environment, 407(24):6143-6149. [doi:10.1016/j.scitotenv.2009.08.039]

Torija, A.J., Ruiz, D.P., Ridao, A.R., 2011. Required stabilization time, short-term variability and impulsiveness of the 
sound pressure level to characterize the temporal composition of urban soundscapes. Applied Acoustics, 72(2-3):89-99. [doi:10.1016/j.apacoust.2010.09.011]

Viollon, S., Lavandier, C., Drake, C., 2002. Influence of visual setting on sound ratings in an urban environment. Applied Acoustics, 63(5):493-511.

Wikipedia, 1996. 100 Soundscapes of Japan. Wikipedia Foundation. Available from http://en.wikipedia.org/wiki/ 100_Soundscapes_of_Japan. [Accessed on June 4, 2012]

Yamada, Y., 2006. Soundscape-based forest planning for recreational and therapeutic activities. Urban Forestry \& Urban Greening, 5(3):131-139. [doi:10.1016/j.ufug. 2006.05.001]

Yang, W., Kang, J., 2005. Acoustic comfort evaluation in urban open public spaces. Applied Acoustics, 66(2): 211-229. [doi:10.1016/j.apacoust.2004.07.011]

Yu, L., Kang, J., 2010. Factors influencing the sound preference in urban open spaces. Applied Acoustics, 71(7): 622-633. [doi:10.1016/j.apacoust.2010.02.005]

Zhang, C., 2001. Quiet Dream Shadows. Central Literature Publishing House, Beijing, China, p.130, 147 (in Chinese).

Zhang, D., 1995. Pottery Recall by Buddhist Nunnery Dreams, The Memory of the West Lake. Writers Publishing House, Beijing, China, p.178 (in Chinese)

Zhang, E.F., 2007. Chinese Traditional Culture. Chongqing Publishing House, Chongqing, China, p.30-31 (in Chinese).

Zhou, Z.J., Gai, L., 2005. The new views on urban environmental noise control by making use of soundscape. Environmental Protection, 2005(12B):43-44 (in Chinese).

Zong, P., 1981. Selected Stories and Prose by Zong Pu. Beijing Publishing House, Beijing, China, p.220-221 (in Chinese). 